\title{
Portfolio Liquidity-Adjusted Value-At-Risk
}

\author{
Marius Botha
}

School of Management, University of the Free State

\begin{abstract}
An important, yet neglected, aspect of risk management is liquidity risk; changes in value due to reduced availability of traded financial instruments. This ubiquitous risk has emerged as one of the key drivers of the developing "credit crunch" with global financial liquidity plummeting since the crisis began. Despite massive cash injections by governments, the crisis continues. Contemporary research has focussed on the liquidity component of single instruments' value-at-risk. This work is extended in this article to measure portfolio value-at-risk, employing a technique which integrates individual instruments' liquidity-adjusted VaR into a portfolio environment without a commensurate increase of statistical assumptions.
\end{abstract}

JEL C1, 2, 5, 13, 22

\section{1}

\section{Introduction}

The Basel Capital Accord, published in 1988, set down the agreement among the G-10 central banks to apply common minimum capital standards to their banking industries by the end of 1992 (BIS, 1988). The standards largely addressed the main risk incurred by banks - credit risk - but five amendments to the Accord were agreed to subsequently and the fifth introduced parallel capital requirements for market risk. A key development of the Basel Accord was the introduction of value-at-risk (VaR), a measure to consolidate an institution's market risk into a single number. The idea was embraced by the finance community and has subsequently come to dominate the field of market risk.

Whilst VaR is not a complex quantity to calculate in principle, estimating its input parameters and determining both their robustness and validity are non-trivial. The late 1980s and most of the 1990s witnessed a profusion of research articles dedicated to the refinement of the VaR measure (Risk Magazine, 2004 and sources therein). Exponential weighting techniques improved volatility and correlation estimates (JP Morgan, 1996), $\mathrm{GARCH}^{1}$ introduced a mean-reverting volatility model (Alexander 2001 and sources therein), alternative distributions were applied to non-Gaussian data (Bouchaudy, 1999) and Extreme Value Theory became a popular measure to elucidate the structure in the datapoor region of distribution tails (McNeil, 1996: 121). Adjustments for portfolios with non-linear pay-off profiles - i.e. comprised in part of options or interest rate dependent instruments - were also introduced and are now standard fare (Ammann \& Reich, 2001: 9).

Changes in market conditions as well as the size and nature of financial risk have necessitated the drafting and construction of Basel II - essentially a revised and augmented framework of Basel I (BIS, 2006). This revision, implemented in Europe in January 2008 (later in the USA), leaves the treatment of market risk largely unchanged from Basel I and instead focuses almost entirely upon the previously neglected areas of credit and operational risk ${ }^{2}$. A large number of research articles are now engaged in the exploration of the complexities of credit and operational risk: market risk articles have consequently diminished significantly in number (Risk Magazine, 2004). The VaR concept, however, has by no means been exhaustively explored: in its standard form it is still plagued by limiting assumptions, but some 
of these standards evade deeper examination on the basis of being "widely-accepted". One such feature is liquidity risk which, because of its tendency to compound other risks, is difficult to isolate and analyse. In all but the most simple of circumstances, comprehensive liquidity risk metrics do not exist and standard VaR models usually ignore liquidity risk completely.

The growth in hedge funds worldwide since the early 2000's, meanwhile, has been explosive, both in terms of number of funds and investment capital (Mulvey, 2003: 24 and HFRX, 2006) and there are increasing indications that the process is accelerating. Ever since the collapse of the Long Term Capital Management (LTCM) hedge fund in August 1998 hedge fund risk managers have been forced to concentrate ever more on liquidity risk (Lowenstein, 2002). It was this aspect of risk - more than any other - that brought LTCM to financial ruin. Despite this, no standard approach for measuring liquidity risk has emerged ${ }^{3}$. Liquidity-adjusted VaR models certainly exist, and some are fairly sophisticated (e.g. Cosandey, 2001: 116), but these are based upon single instrument VaR approaches and their application to portfolios is not uniform. Less sophisticated approaches such as those that rely on conventional measures of leverage to estimate liquidity risk sometimes provide meaningless results (Bangia, 1999: 70). In addition, the existence of both endogenous and exogenous liquidity risk (which are quite different in both structure and manifestation), autocorrelation and scaling in time of return data and the aggregation of single-instrument liquidity $\mathrm{VaR}$ into portfolio liquidity $\mathrm{VaR}$ (Umut, 2004: 315) all involve non-trivial and computer-intensive implementation.

This article explores the dual and related problems of:

1. adjusting for endogenous liquidity (without invoking the square root of time rule),

2. the incorporation of individual liquidityadjusted VaRs into portfolio liquidityadjusted VaR

and introduces a technique to integrate these twin methodologies.

Section 2 explores the available literature on liquidity risk from an endogenous and exogenous viewpoint. The calculation of each with associated implementation difficulties - is also discussed here.

A brief literature survey on associated topics, such as the scaling of volatility with the square root of time and the autocorrelation of equity returns, are also examined. This section is by no means exhaustive and aims to provide only a general background to what is rapidly becoming a large body of research.

Section 3 provides a brief overview of the mathematical complexity of endogenous liquidity risk and provides the basis for extending previous work. The problems and limitations of the current research are explored and some questions are posed which are then answered in Section 4, which introduces a formal explanation of a new portfolio liquidity VaR measure. Section 5 presents the results of simulation trials conducted on market data and Section 6 concludes the article.

\section{2}

\section{Liquidity risk}

Liquidity may be defined as a range of characteristics rather than a one-dimensional attribute of assets and of the markets on which they are traded. It is also a relative concept, as the more liquid the asset, the more easily it is traded for cash, i.e. at low cost, at short notice and with no risk of a notable change in price. A perfectly liquid market would therefore guarantee a single bid/ask price at all times, irrespective of the quantities being traded. Financial markets, even those deemed most liquid, conform less than perfectly to this ideal configuration. Liquidity risk is thus the risk of being unable to liquidate or hedge a position immediately and at current market prices.

The use of VaR as the standard market risk measure has enjoyed ever-increasing popularity since its formulation in the late 1980s: it is now the most widely-used risk metric for the determination of market risk (Holton, 2003: 405). Whilst considerable attention has been given to the measurement of financial instrument volatility and correlation as well as the incorporation of these values into portfolio $\mathrm{VaR}$, the liquidity risk of these instruments 
remains severely under-examined. It is included in standard VaR calculations only in an ad hoc fashion, namely by increasing the time horizon over which VaR is calculated to account for the time taken to liquidate a large position (JP Morgan, 1996). Not only does this technique not distinguish between exogenous and endogenous liquidity (defined and discussed below), but it employs the "square root of time" rule, in which it is assumed that no autocorrelation exists between rates of return from one measurement period to another. This assumption of a lack of autocorrelation allows for simple arithmetic summation of individual variances to produce the overall "period under investigation" variance. Thus, for example:

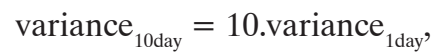

and, as a direct consequence this leads to the statistical conclusion that:

$\sigma_{10 \text { day }}=\sqrt{10} \cdot \sigma_{1 d a y}$.

This assumption has been challenged over the past decade by several authors (see for example, Diebold (1996) and Blake et al., (2000)). In addition, Danielsson and Zigrand (2006: 2711) recently again demonstrated that the square root of time rule leads to a systematic underestimation of risk - but also found that the degree of underestimation worsens with time horizon, jump intensity and confidence level. They conclude that despite the widespread application and implementation of the square root of time rule in the Basel regulatory accords, it nevertheless fails to address the objective of the Basel accords. It is clear that a more thorough investigation into the nature of liquidity risk and its effect on portfolios of illiquid instruments is required.

Two types of liquidity risk have been identified, namely exogenous and endogenous liquidity risk. These are defined below.

(a) Exogenous liquidity risk is the result of market characteristics; it is common to all market players and unaffected by the actions of any one participant (Bangia et al., 1998). In response to a market shock (and the resultant loss of predictability), a vicious cycle with a corresponding loss of liquidity is initiated. The perceived need to hold larger prudential reserves in situations of greater uncertainty along with reduced liquidity and leverage may not break the self-reinforcing dynamics of market dislocations. Exogenous liquidity can be affected by the joint action of all or almost all market participants as occurred in several markets in the summer of 1998 (Lowenstein, 2002). The market for liquid securities, such as G7 currencies, is typically characterised by heavy trading volumes, stable and small bid-ask spreads, stable and high levels of quote depth. Liquidity costs may be negligible for such positions when marking to market provides a proper liquidation value. In contrast, markets in emerging currencies or thinly traded junk bonds are illiquid and are characterised by high volatilities of spread, quote depth and trading volume.

(b) Endogenous liquidity risk, in contrast, is specific to the position in the market and varies across market participants (Bangia et al., 1998). The exposure of any one participant is affected by the actions of that participant. It is mainly driven by the size of the position: the larger the size, the greater the endogenous illiquidity. If the market order to buy/sell is smaller than the volume available in the market at the quote, then the order transacts at the quote. In this case the market impact cost, defined as the cost of immediate execution, will be half of the bid-ask spread. If the size of the order exceeds the quote depth, the cost of market impact will be higher than the halfspread. The difference between the total market impact and half-spread is called the incremental market cost, and constitutes the endogenous liquidity component.

Le Saout (2002) reported that neither exogenous liquidity risk (which accounts for about half of total market risk) nor endogenous liquidity risk (also a potentially significant component of market risk) should be ignored by financial institutions subject to market risk.

This section introduced liquidity risk as an autonomous and important component of 
overall portfolio risk and provided broad definitions of the different types of liquidity encountered in the market. The following section supplies a literature review of relevant liquidity risk research.

\section{3}

\section{Literature survey}

Recent work has begun to incorporate vanishing liquidity in times of crisis. Le Saout (2002) provides a good review of liquidity risk in VaR models and gives a comprehensive overview of recent research in the field.

Lawrence and Robinson (1995: 64) were among the first to identify and establish that conventional VaR models often exclude asset liquidity risk. They argued that the best way to capture liquidity issues within the VaR framework would be to match the VaR time horizon with the time investors believed it could take to exit or liquidate the portfolio. They established that the liquidation of a portfolio over several trading days generated additional liquidity costs.

Diebold et al. (1996) pointed out that the scaling of volatilities by the square root of time is only applicable if log changes of price returns are i.i.d. (independently and identically distributed) and, in addition, normally distributed. They noted that high frequency financial asset returns are not i.i.d. and that, even if they are conditional mean independent they are definitely not mean variance independent (see also Bollersev, Chou \& Kroner 1992: 20 and Diebold \& Lopez 1995: 433 for evidence of strong volatility persistence in financial asset returns.) Diebold et al. (1996) showed that scaling by the square root of time magnifies the volatility fluctuations i.e. scaling results in large conditional variance fluctuations of long horizon returns, when in fact the opposite is true.

Jarrow and Subramanian (1997: 171, 2001: 450) considered optimal liquidation of an investment over a fixed horizon. They characterised the costs and benefits of block sales versus slow liquidation and they proposed an endogenous liquidity adjustment to the standard VaR measure. The model requires three quantities which increase the loss level
- namely a liquidity discount, the volatility of the liquidity discount and the volatility of the time horizon to liquidation. The authors themselves acknowledge that traders or firms must collect time series data on the shares traded, prices received and time to execution in order to estimate these quantities. Whilst this model is robust and fairly easy to implement, estimating these quantities is by no means trivial. Indeed, some may only be determined empirically with the accompanying introduction of significant bias.

Fernandez (1999: 2) examined liquidity risk in the aftermath of the 1998 LTCM liquidity crisis. He argued that:

“...financial markets are undergoing rapid structural change, which may be contributing to liquidity risk. These changes along with rising homogeneity of market participants' behaviour are increasing concentration and 'herding behaviour' and eliminating 'friction' which may prove disadvantageous in a market correction."

(Fernandez, 1999: 3)

Fernandez concluded that no single measure captured the various aspects of liquidity in financial markets, but rather a composite of measures, incorporating quantitative and qualitative factors. His treatment of the problem, however sound, does not address the mathematical issues underlying this complex problem.

Bangia et al. (1999: 71) explored exogenous liquidity risk. They treated the liquidity risk and market risk jointly and made the assumption that in adverse market environments extreme events in returns and extreme events in spreads occur concurrently. They noted that while the correlation between mid-price movements and spreads was not perfect - it was strong enough during extreme market conditions to encourage the treatment of extreme movements in market and liquidity risk simultaneously. They incorporated both a $99^{\text {th }}$ percentile movement in the underlying and a $99^{\text {th }}$ percentile movement in the spread.

Almgren and Chriss (1999: 59) examined endogenous liquidity risk by considering the problem of portfolio liquidation. They aimed 
to minimise a combination of volatility risk and transaction costs arising from permanent and temporary market impact. From a simple linear cost model, they built an efficient frontier in the space of time-dependant probability. They considered the risk-reward trade-off both from the point of view of classic mean-variance optimisation and the standpoint of VaR. Their analysis led to general insights into optimal portfolio trading, and to several applications including a definition of liquidity-adjusted VaR.

Hisata and Yamai (2000: 84) proposed a practical framework for the quantification of liquidity-adjusted value-at-risk which incorporated the market liquidity of financial products. Their framework incorporates the mechanism of the market impact caused by the investor's own dealings through adjusting Valueat-Risk according to the level of market liquidity and the scale of the investor's position. In addition, Hisata and Yamai (2000: 86) proposed a closed-form solution for calculating liquidityadjusted VaR as well as a method of estimating portfolio liquidity-adjusted VaR.

Erwan (2002: 11) demonstrated that the standard value-at-risk model largely neglects the liquidity aspect of market risk because no single measure captures the various aspects of liquidity in financial markets. Erwan (2002: 8) extended the liquidity adjusted value-at-risk model developed by Bangia et al. (1999) by incorporating a weighted average spread to bid and offer prices and applied the resulting model to the French stock market. Both endogenous and exogenous liquidity risk were found to be important components of market risk.

Çetin et al. (2004) approach assumes the existence of a stochastic supply curve for a security's price as a function of transaction size. Specifically, a second argument incorporates the size (number of shares) and direction (buy versus sell) of a transaction to determine the price at which the trade is executed. For a given supply curve, traders act as price takers. The more liquid an asset, the more horizontal its unique supply curve. In the context of continuous trading, necessary and sufficient conditions on the supply curve's evolution are characterised such that no arbitrage opportunities arise in the economy. Furthermore, given an arbitrage free evolution for the supply curve, conditions for an approximately complete market are also provided. In the most general setting with unrestricted predictable trading strategies, Çetin et al. obtain three primary conclusions with respect to the pricing of derivatives. First, all liquidity costs are avoidable when (approximately) replicating a derivative's payoff using continuous trading strategies of finite variation. Second (and as a consequence of the previous conclusion) the derivative's price is the price obtained by ignoring the bid-ask spread and other illiquidities. Third, no implied bid-ask spreads or illiquidities exist for a derivative's price. Note that these conclusions follow from continuous trading of infinitesimal quantities. Although related mainly to derivative pricing, this work was used by Jarrow and Protter (2005: 9) to modify current risk measures to account for liquidity risk, though they admit that although more complex adjustments are possible, these await subsequent research.

Angelidis and Benos (2005) relaxed the traditional, yet unrealistic, assumption of a perfect, frictionless financial market (i.e. investors can either buy or sell any amount of stock without causing significant price changes). Angelidos and Benos extended the work of Hausman et al. (1992: 323) and Madhavan et al. (1997: 1041) (who argued that traded volume can explain price movements) and developed a liquidity VaR measure based on spread components, following the work of Bangia et al. (1999: 72). Under this framework, the liquidity risk was decomposed into its endogenous and exogenous components, thereby permitting an assessment of the liquidation risk of a specific position. As with much other research, this relevant and detailed work does not address portfolio liquidity - the chief focus of this article.

The problem of ignoring liquidity risk is amplified in - but not confined to portfolios which consitute - hedge funds. Hedge fund manager styles were addressed by LHabitant (2000: 12, 2001: 18) who noted that there was a need to introduce new quantitative tools to assist investors assessing the investment characteristics and the risks of hedge funds. Using only net asset 
values from a hedge fund, LHabitant proposed a methodology to identify strategic and tactical hedge fund asset allocations and compare their performance against an ad-hoc benchmark. The method on which he relied was a returns-based style analysis introduced by Sharpe (1988). LHabitant also notes that:

"...there are numerous directions for future research. In particular, the framework presented in this paper does not incorporate all the risk components to which a hedge fund investor is exposed. For instance, we have completely omitted credit and liquidity risks, which are also essential parts of the full risk picture of a hedge fund." (LHabitant, 2001: 13).

This section provided a literature review of recent research in the field of liquidity risk as well as insight into some of the methods which have been developed to mitigate and manage it. Hisata and Yamai (2000: 90) provide - to our knowledge - the only coherent portfolio approach to liquidity risk. The next section will explore the possibility of combining Jarrow and Subramanian's $(1997,2001)$ - henceforth JS-model (for evaluating individual instrument liquidity-adjusted VaR - henceforth LVaR) and standard portfolio theory to produce a robust portfolio LVaR approach under normal trading conditions, i.e. endogenous liquidity risk. This technique represents a variation on Hisata and Yamai's (2000: 90) portfolio approach, but also incorporates several elements discussed by them. The aim is thus to construct a liquidityadjusted $\mathrm{VaR}(\mathrm{LVaR})$ at a portfolio level.

\section{4}

\section{Liquidity value-at-risk}

Whilst many LVaR models exist, the JS model is increasing in importance as the endogenous liquidity model of choice (for example, see Umut (2004: 322). Although Çetin's (2004) work is currently enjoying some popularity - see Jarrow and Protter (2005: 12) - more work is required before the adjustments recommended can be effectively and robustly implemented into existing VaR models). The JS model's results will be used later to combine individual LVaRs into a portfolio LVaR. No attempt will be made here to reproduce in full the underlying theoretical framework of the JS model. Nevertheless, it is instructive to provide a brief summary of the structure and constituents of the JS model equations. Having established this JS model overview, the individual instrument LVaRs will be combined using standard portfolio theory to produce a portfolio LVaR equation. This formula will then be tested on actual profit and loss and accompanying non-liquidity-adjusted VaR data from several South African equity portfolios and the results compared.

The equation governing liquidity adjusted VaR according to the JS model is given by:

$$
L V a R_{J S}=\rho . S \cdot\left[\mu \cdot\{E(\Delta S)+E(\ln [c(S)])\}-C I\left(\sigma_{E} \cdot \sqrt{E(\Delta S)}+|\mu| \cdot \sigma_{\Delta S}+\sigma_{\ln [c(S)]}\right)\right]
$$

where

$\rho \quad$ is the quantity of equity purchased (or short-sold)

$S \quad$ is the equity price (hence $\rho \times S$ is essentially the nominal amount invested: ie quantity $\times$ price)

$\mu \quad$ is the average portfolio return

$E(\Delta S)$ is the expected value of the time horizon to liquidation

$c(S)$ is the liquidity discount - ie the difference between the market value of a trader's position and its value when it is ultimately liquidated

$C I$ is the confidence interval

$\sigma_{\Delta S}$ is the volatility of the time horizon to the position's liquidation

$\sigma_{E} \quad$ is the equity return volatility and

$\sigma_{\ln [c(S)]}$ is the volatility of the natural logarithm of the liquidity discount. 
The standard parametric VaR equation (Dowd et al.., 2003) is given by:

$V a R=N \cdot\left(\mu \cdot T-C I \cdot \sigma_{p} \cdot \sqrt{T}\right)$

where

$N$ is the notional investment amount

$\mu$ is the average $T$-period return ${ }^{4}$

$\sigma_{p}=\sqrt{\left(\begin{array}{ll}w_{A} & w_{B}\end{array}\right) \cdot\left(\begin{array}{cc}\sigma_{A}^{2} & \sigma_{A} \sigma_{B} \rho_{A B} \\ \sigma_{B} \sigma_{A} \rho_{B A} & \sigma_{B}^{2}\end{array}\right) \cdot\left(\begin{array}{l}w^{A} \\ w_{B}\end{array}\right)}$

where $\mathrm{w}_{\mathrm{A}}$ and $\mathrm{w}_{\mathrm{B}}$ are the investment weights in the respective equities, $\sigma_{A}$ and $\sigma_{B}$ are the respective equity return volatilities and $\rho_{A B}$ is the correlation between the equity returns of $\mathrm{A}$ and $\mathrm{B}$. The central matrix under the square root is the covariance matrix. The diagonals are the constituent variances and the off-diagonal terms are identical since the matrix is positive semi-definite.

Mechanisms which govern equity risk are broadly similar - regardless of the models used to describe these. It is therefore no coincidence that the JS model (Equation 1) closely resembles the parametric VaR equation (Equation 2) in which the terms $N . \mu . T \quad$ and $\quad \rho . S . \mu\{E(\Delta S)+E(\ln [c(S)])\}$ are analogous as are the $C I . \sigma_{p} \cdot \sqrt{T}$ and $C I .\left(\sigma_{E} \cdot \sqrt{E(\Delta S)}+|\mu| \cdot \sigma_{\Delta S}+\sigma_{\ln [c(S)]}\right)$ terms.

Using the common assumption that the average portfolio return is sufficiently small to
$C I$ is the confidence interval

$\sqrt{T}$ is the square root of the time horizon to liquidation ${ }^{5}$ and

$\sigma_{p}$ is the portfolio volatility.

Using matrix notation, the portfolio volatility, $\sigma_{p}$, for two stocks ${ }^{6} \mathrm{~A}$ and $\mathrm{B}$, is written as (Dowd et al., 2003):

be considered equal to 0 per cent (JP Morgan, 1996: 8), Equation 1 simplifies to

$\operatorname{LVaR}_{\mathrm{JS}}=\rho . S . C I\left(\sigma_{E} \cdot \sqrt{E(\Delta S)}+\sigma_{\ln [c(S)]}\right)$

and Equation (2) to:

$\mathrm{LVaR}_{\text {simple }}=N \cdot C I \cdot \sigma_{p} \cdot \sqrt{T}$

where the portfolio $V a R, V a R p$, has been replaced in Equation 5 with $L V a R_{\text {simple }}$ or the "simple liquidity adjusted VaR" since the square root of time term reflects the simple manner in which liquidity is taken into account in the standard $\mathrm{VaR}$ model.

The goal now is to expand the mathematics of Equations 4 and 5 (liquidity-adjusted VaRs for single instruments) to incorporate portfolios of instruments.

Using Equation 3, Equation 5 may be written (in matrix notation):

$\operatorname{LVaR}_{\text {simple }}=N \cdot C I \cdot \sqrt{\left(\begin{array}{ll}w_{A} & w_{B}\end{array}\right) \cdot\left(\begin{array}{cc}\sigma_{A}^{2} & \sigma_{A} \sigma_{B} \rho_{A B} \\ \sigma_{B} \sigma_{A} \rho_{B A} & \sigma_{B}^{2}\end{array}\right) \cdot\left(\begin{array}{c}w_{A} \\ w_{B}\end{array}\right) \cdot \sqrt{T}}$

Decomposing the covariance matrix into its constituent volatilities and correlation matrices gives:

$L V a R_{\text {simple }}=N \cdot C I \cdot \sqrt{\left(w_{A} \sigma_{A} w_{B} \sigma_{B}\right) \cdot\left(\begin{array}{cc}1 & \rho_{A B} \\ \rho_{B A} & 1\end{array}\right) \cdot\left(\begin{array}{cc}w_{A} \sigma_{A} \\ w_{B} \sigma_{B}\end{array}\right)} \cdot \sqrt{T}$

Extending the square root and incorporating the notional investment and liquidation horizon gives:

$\operatorname{LVaR}_{\text {simple }}=\sqrt{\left(N \cdot w_{A}\left(C I \cdot \sigma_{A}\right) \cdot \sqrt{T} \quad N \cdot w_{B}\left(C I \cdot \sigma_{B}\right) \cdot \sqrt{T}\right) \cdot\left(\begin{array}{cc}1 & \rho_{A B} \\ \rho_{B A} & 1\end{array}\right) \cdot\left(\begin{array}{l}N \cdot w_{A}\left(C I \cdot \sigma_{A}\right) \cdot \sqrt{T} \\ N \cdot w_{B}\left(C I \cdot \sigma_{B}\right) \cdot \sqrt{T}\end{array}\right)}$ 
which may be rewritten as:

$L V a R_{\text {simple }}=\sqrt{\left(\operatorname{LVaR}_{\text {simple }}^{A} L V a R_{\text {simple }}^{B}\right) \cdot\left(\begin{array}{cc}1 & \rho_{A B} \\ \rho_{B A} & 1\end{array}\right) \cdot\left(\begin{array}{l}L V a R_{\text {simple }}^{A} \\ L V a R_{\text {simple }}^{B}\end{array}\right)}$

where

$L V a R_{\text {simple }}^{A}=N \cdot w_{A} \cdot C I \cdot \sigma_{A} \cdot \sqrt{T}$ and $L V a R_{\text {simple }}^{B}=N \cdot w_{B} \cdot C I \cdot \sigma_{B} \cdot \sqrt{T}$.

It is not unreasonable to conclude, in an analogous manner to Equation 6, that $L V R_{\mathrm{JS}}$ (Equation 4) may be written:

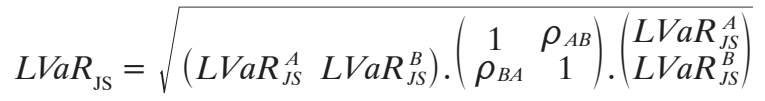

where the component $L V a R_{\mathrm{JS}}$ are defined by Equation 4.

Equations 6 and 7 both purport to estimate the portfolio liquidity adjusted VaR. Since VaR is a one day forecast of a portfolio's P\&L, the VaR may be calculated using Equations 4 and 5 above and the results may be compared with realised $\mathrm{P} \& \mathrm{~L}$ from portfolio returns.

In order to compare results, data from 14 South African equity portfolios were assembled. These included realised P\&L data as well as all of the required inputs for both the $L V a R_{\mathrm{JS}}$ model (Equation 4) and the $L V a R_{\text {simple }}$ model (Equation 5).

The quantity of equity purchased, $\rho$, is determined using actual trading quantities executed, ie successful bids or offers. Equity prices, $S$, are determined at the time of the transaction's execution, while the expected value of the time horizon to liquidation $-E(\Delta S)$ - is the simple average time taken between placing a bid/offer and the successful execution of the transaction. The liquidity discount, $c(S)$, measures the difference between the market value of traders' positions at the time of bid/ offer and the value when they are ultimately liquidated. The volatility of this time horizon (from bid/offer to the position's liquidation), $\sigma_{\Delta S}$, may also be estimated from liquidity discount data, $c(S)$, and $\sigma_{E}$ is the exponentially weighted moving average volatility of the equity data. The volatility of the natural logarithm of the liquidity discount, $\sigma_{\ln [c(S)]}$, may also be estimated from liquidity discount data, $c(S)$.

Liquidity adjusted VaRs were estimated using Equations 6 and 7. Correlation values for both methods were determined using a 250-day rolling window of equity returns and the exponentially weighted moving average technique (JP Morgan, 1996: 78) with decay constant $\lambda=0.92$ for South African equities.

These data provide an opportunity to back test the VaR forecasts using both the simple approach (Equation 5) and the JS model approach (Equation 4) against realised P\&Ls. The results of this investigation are presented in the following section.

\section{5 \\ Results}

The forecast $L V a R_{\mathrm{JS}}$ (Equation 7) was calculated for each equity portfolio, using parameters obtained from portfolio data and compared with the daily forecast 95 per cent $L V a R_{\text {simple }}$ (Equation $6)$. These are shown for only four different portfolios $^{7}$ in Figure 1(a) through (d). In line with common practice, the measured daily $\mathrm{P} \& \mathrm{~L}$ is indicated on the same graph in each case (as a means of comparing forecast 95 per cent VaR with realised P\&Ls). 


\section{Figure 1}

Realised P\&Ls, simple 95\% $\mathrm{LVaR}_{\text {simple }}$ and 95\% $\mathrm{LVaR}_{\mathrm{JS}}$ for four separate equity portfolios (a) through (d) over a 466-day period between January 2004 and November 2006
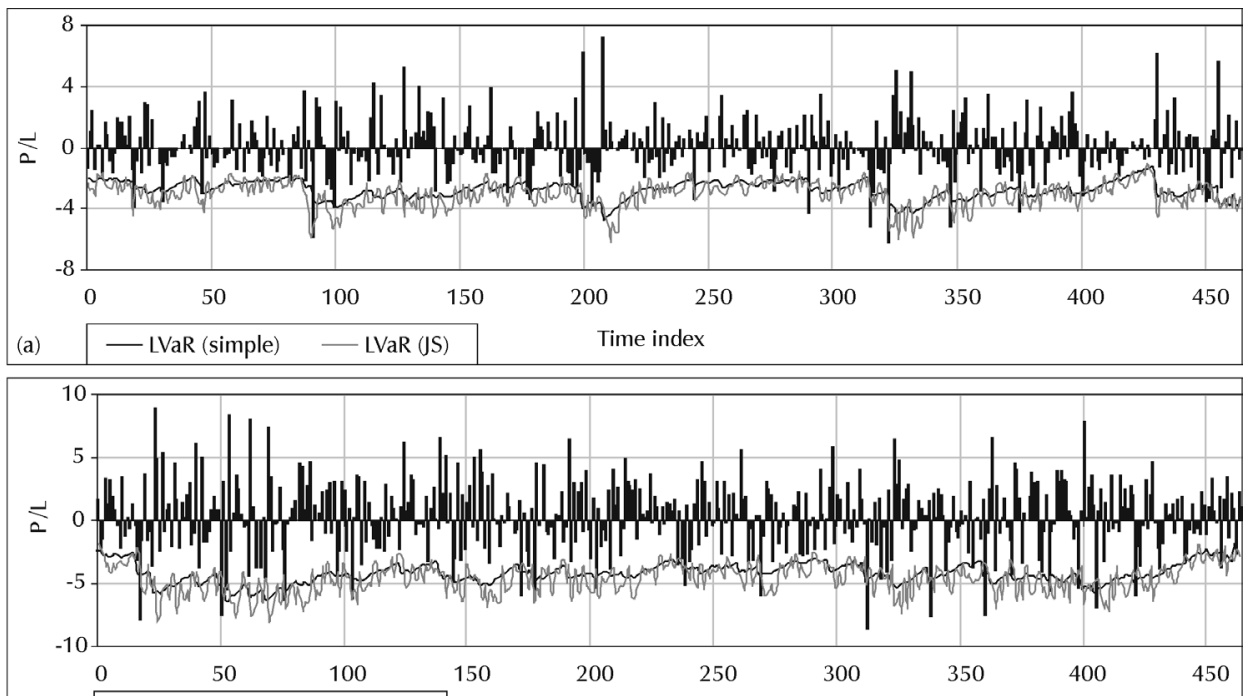

(b) - LVaR (simple) — LVaR (JS) Time index
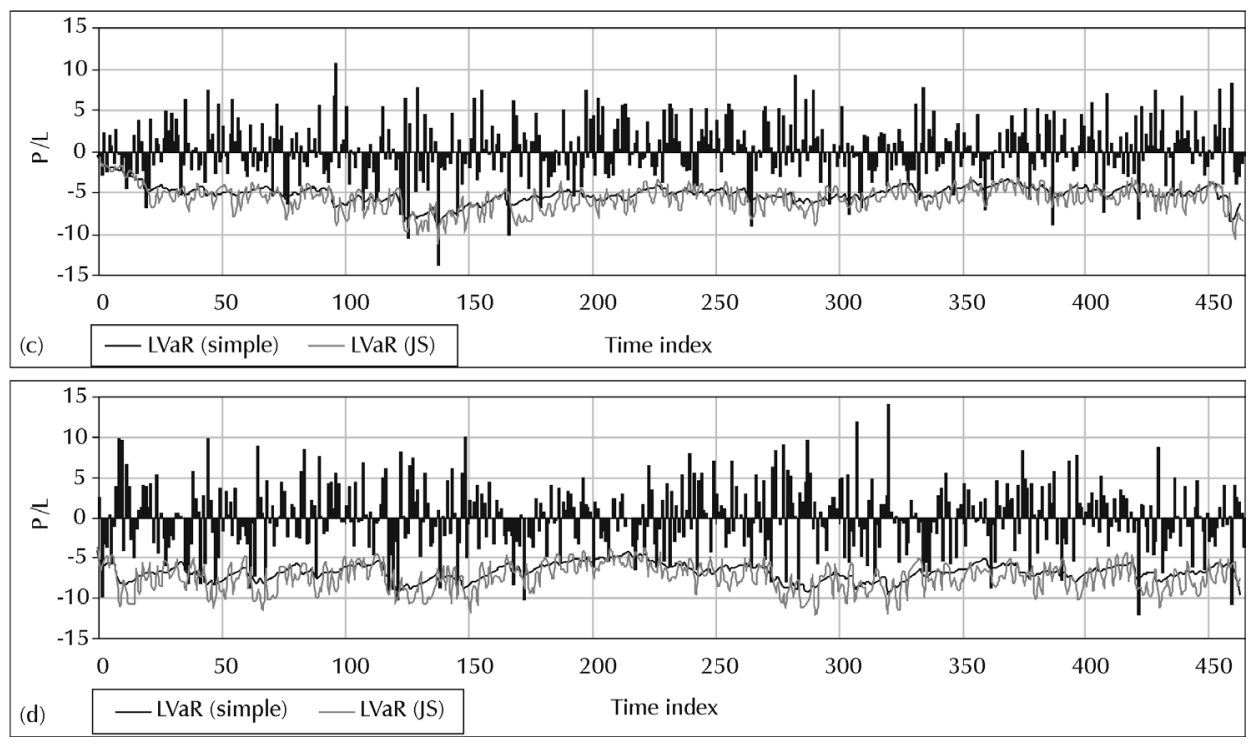

The $L V a R_{\mathrm{JS}}$ were found to be more volatile than the $L V a R_{\text {simple }}$, due to the combination of the two volatility terms, namely $\sigma_{E} \sqrt{E(\Delta S)}$ and $\sigma_{\ln [c(S)]}$ over short timescales (days), but the two LVaR terms track one another closely over longer timescales (months).
A section of data (100 days) was selected from the portfolio represented in Figure 1(a) to highlight obscured detail. These are shown in Figure 2. The circled regions show four cases in which the $L V a R_{\text {simple }}$ forecast the VaR incorrectly, whilst the $L V a R_{\mathrm{JS}}$ succeeded. 


\section{Figure 2}

Detail of time series (100 days) selected from fund P/L data represented in Figure 1(a)

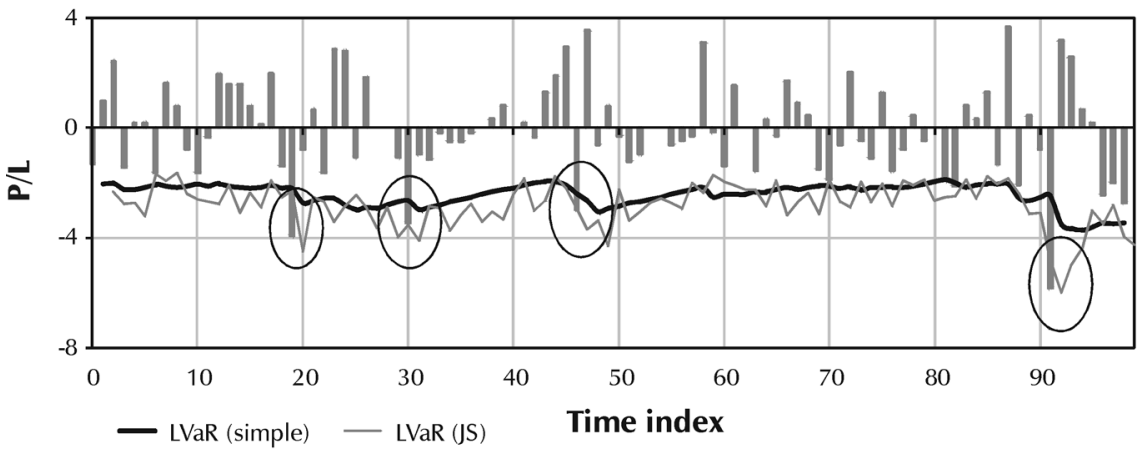

Back testing the accuracy of VaR forecasts against realised $\mathrm{P} \& \mathrm{~L}$ is not only common practice but also a requirement by many bank regulators to establish the validity of banks' internal VaR models. The Basel committee (BIS, 2004) has stipulated that, for VaR measured at a 95 per cent confidence interval over 250 days, a maximum of five exceptions (ie cases in which the forecast VaR underestimated the following day's P\&L) are allowed over and above the 5 per cent expected exceptions (due to the 95 per cent confidence interval). The more exceptions that occur than those allowed by the Basel accord incur greater and greater capital charges for market risk up to a maximum of ten. If more than ten exceptions in a 250 day period occur, the regulator will order an investigation into the bank's market risk model. Since it is in the best interests of banks to install and maintain accurate VaR models, the returns from 14 equity portfolios were back tested to ascertain the accuracy of the two liquidityadjusted VaR models.

Using the 466 days of data used to generate Figure 1, the number of exceptions (ie instances in which VaR forecasts underestimated the following day's losses) were measured using both $L V a R_{\text {simple }}$ and $L V a R_{\mathrm{JS}}$ for all 14 portfolios in this sample. Whilst it is expected that 5 per cent of forecasts will be 'outliers' or exceptions - by definition - Table 1 (and Figure 3 ) below shows that the 95 per cent $L V a R_{\mathrm{JS}}$ forecast estimate is the more accurate than the 95 per cent $L V a R_{\text {simple }}$, especially at times of high market turbulence (ie times of potential reduced liquidity).

\section{Table 1}

Comparison of 95\% LVaR forecast exceptions measured over 466 days for all portfolios. Note that $5 \% \times 466=23$ exceptions are expected

\begin{tabular}{|c|c|c|c|c|}
\hline \multirow{2}{*}{$\begin{array}{c}\text { Fund } \\
\text { number }\end{array}$} & \multicolumn{2}{|c|}{$\mathbf{9 5}$ per cent $\boldsymbol{L V a}_{\text {simple }}$} & \multicolumn{2}{c|}{$\mathbf{9 5}$ per cent $\boldsymbol{L V a}_{\mathrm{IS}}$} \\
\cline { 2 - 5 } & Exceptions & \% of total (5\% expected) & Exceptions & \% of total (5\% expected) \\
\hline 1 & 25 & $5.38 \%$ & 17 & $3.66 \%$ \\
\hline 2 & 25 & $5.38 \%$ & 20 & $4.30 \%$ \\
\hline 3 & 35 & $7.53 \%$ & 28 & $6.02 \%$ \\
\hline 4 & 33 & $7.10 \%$ & 25 & $5.38 \%$ \\
\hline 5 & 31 & $6.67 \%$ & 24 & $5.16 \%$ \\
\hline 6 & 31 & $6.67 \%$ & 26 & $5.59 \%$ \\
\hline
\end{tabular}




\begin{tabular}{|r|l|l|l|l|}
\hline 7 & 30 & $6.45 \%$ & 25 & $5.38 \%$ \\
\hline 8 & 33 & $7.10 \%$ & 29 & $6.24 \%$ \\
\hline 9 & 26 & $5.59 \%$ & 22 & $4.73 \%$ \\
\hline 10 & 25 & $5.38 \%$ & 21 & $4.52 \%$ \\
\hline 11 & 33 & $7.10 \%$ & 27 & $5.81 \%$ \\
\hline 12 & 27 & $5.81 \%$ & 22 & $4.73 \%$ \\
\hline 13 & 26 & $5.59 \%$ & 20 & $4.30 \%$ \\
\hline 14 & 26 & $5.59 \%$ & 22 & $4.73 \%$ \\
\hline
\end{tabular}

Figure 3

Graphical comparison of VaR forecast accuracy for both $\mathrm{LVaR}_{\text {simple }}$ and $\mathrm{LVaR}_{\mathrm{JS}}$ techniques clearly showing - for all portfolios - superior accuracy using the latter

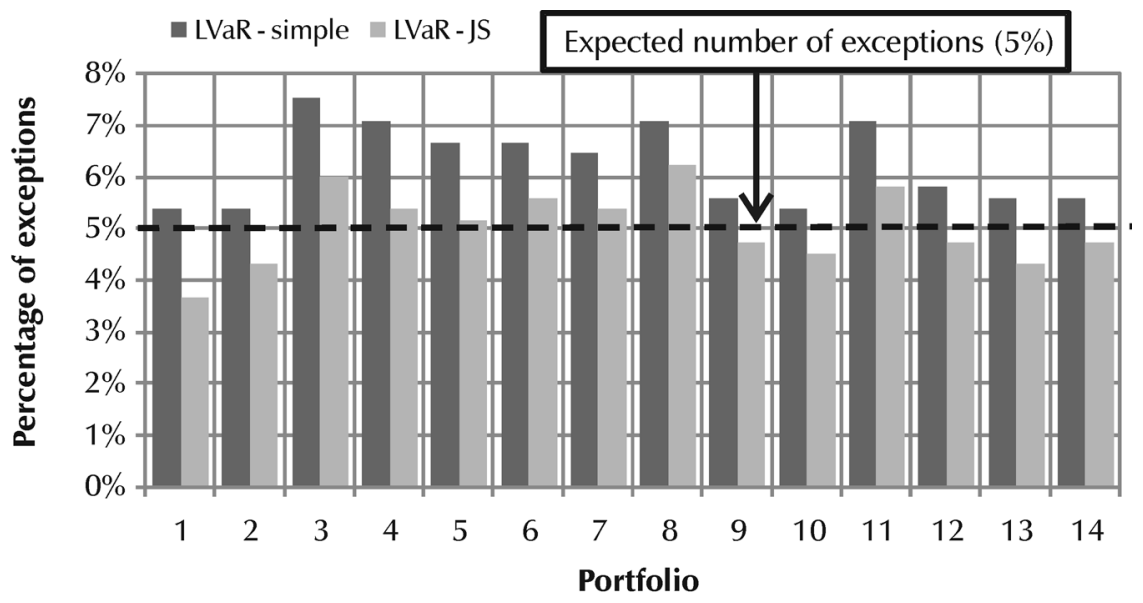

VaR has been criticised for failing to forecast the degree of inaccuracy should an exception occur. Although this gap has been largely plugged by expected shortfall (ES) measures (Yamai and Yoshiba, 2002), the accuracy of liquidity VaR measures could be compared using the portfolio data from this study. Thus, in addition to the number of exceptions, the Rand difference between realised P\&L and forecast VaR was also determined using both measures of liquidity VaR. The results are shown in Figure 4 below. For each of the 14 portfolios here investigated - each using 466 data points - the $L V a R_{\text {simple }}$ measure underestimated actual losses to a greater extent than the $L V a R_{\mathrm{JS}}$. For $L V a R_{\text {simple }}$ the average underestimation was 7.5 per cent with a standard deviation, $\sigma=3.1$ per cent while for $L V a R_{\mathrm{JS}}$ the average underestimation was only 4.2 per cent with $\sigma=1.9$ per cent. 


\section{Figure 4}

Comparison of VaR forecast versus realised $P \& L$ for both $L_{V a R}$ simple and $L_{V a R}$ techniques.

For all portfolios, the latter's estimated losses were more accurately forecast.

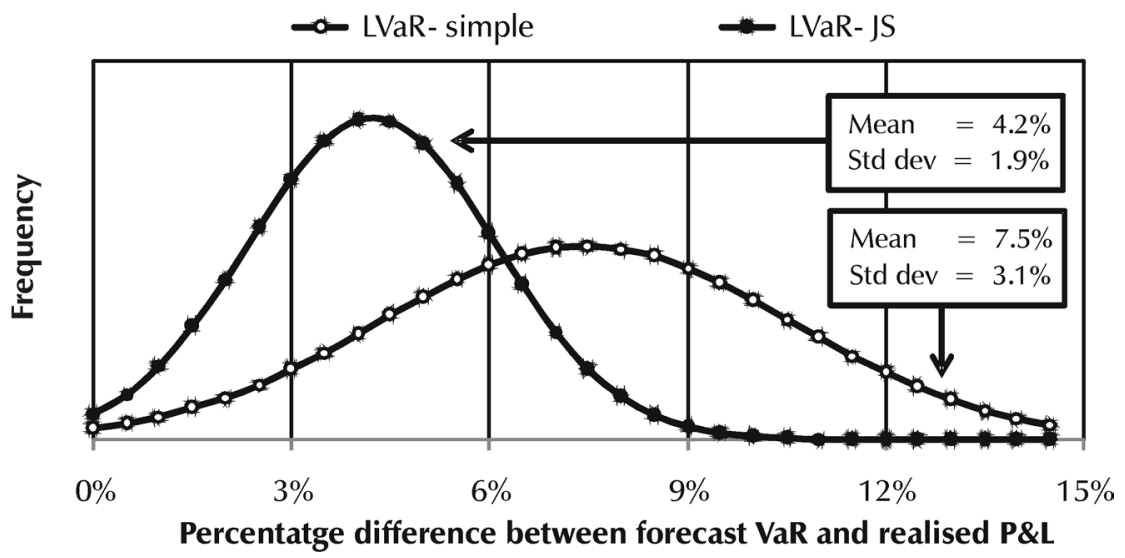

6

\section{Conclusion}

LVaR using the JS methodology has been successfully incorporated into a portfolio framework. It has been shown to be superior to LVaR estimated using the simple square root of time technique using realised $\mathrm{P} / \mathrm{L}$ (in terms of both frequency of underestimation and accuracy of $P \& L$ estimation) values as a comparison. Simple LVaR employs only the square root of time as a suitable scaling factor to accommodate liquidity constraints, while the JS LVaR model uses the JS approach to liquidity risk. The latter has already been demonstrated to be superior to the square root of time model at the individual instrument level (Jarrow \& Subramanian, 1997: 172).

The implementation of the JS model is by no means simple: obtaining and estimating the required parameters is onerous and requires constant recalculation to accommodate the rapidly changing portfolio LVaR. However, these parameters are available (though often not disclosed publicly) and, having them, incorporation into a portfolio model is relatively straightforward and requires only knowledge of the linear correlations between equity returns to complete the calculation as well as a technique borrowed from standard portfolio theory.
The payoff received from this complex calculation is a much-improved VaR forecast with greater accuracy than that obtained from standard VaR models.

\section{Endnotes}

1 Generalised Autoregressive Conditional Heteroscedasticity.

2 The Bank's primary exposure to counterparty credit risk is through its investment portfolio, however, it can also have exposure to derivative counterparties (which may default on obligations) in the trading book. Banks seek to minimise the risk that a credit loss from a counterparty default or downgrade could cause either a financial loss or damage the Bank's reputation. Basel II addresses this counterparty risk problem in detail, but leaves the basic tenets of the measurement and management of market risk untouched (BIS, 2005).

3 This study is by no means confined to the risks associated with hedge funds - these funds merely amplify the effects of liquidity risk through their unique investment strategies.

4 It is commonly assumed that $\mu=0$ (JP Morgan, 1996: 8).

5 In the standard parametric equation, only the term $\sqrt{T}$ is assumed to adjust for market illiquidity.

6 This portfolio volatility equation may, of course, be extended for $n$ stocks.

7 Similar results were obtained for the remaining ten portfolios in the data sample. 


\section{References}

1 ALEXANDER, C. (2001) Market Models: A Guide to Financial Data Analysis, Wiley: London.

2 ALMGREN, R. \& CHRISS, N. (1999) "Value under liquidation", Risk, December: 58-64.

3 AMMAN, M. \& REICH, C. (2001) "VaR for nonlinear financial instruments - linear approximation or full Monte Carlo?", Financial Markets and Portfolio Management, 15: 1-18.

4 ANGELIDIS, T. \& BENOS, A. (2005) "Liquidity adjusted value-at-risk based on the components of the bid-ask spread", http://ssrn.com/ abstract $=661281$ [Date accessed: 31 August 2007]

5 BANGIA, A.; DIEBOLD, F.X.; SCHUERMANN, T. \& STROUGHAIR, J. (1998) "Modelling liquidity risk", www.ssc.upenn.edu/ fdiebold/ papers/paper25/bds.pdf [Date accessed: 22 September 2006]

6 BANGIA, A.; DIEBOLD, F.X.; SCHUERMANN, T. \& STROUGHAIR, J. (1999) "Liquidity on the outside", Risk, 12: 68-73.

7 BIS (1988) "International convergence of capital measurement and capital standards", www.bis. org/publ/bcbs04a.htm [Date accessed: 12 August 2006]

8 BIS (2004) "International convergence of capital measurement and capital standards: A revised framework", www.bis.org/publ/bcbsca.htm [Date accessed: 17 December 2006]

9 BIS (2005) "The application of Basel II to trading activities and the treatment of double default effects", www.bis.org/publ/bcbs111.htm [Date of access: 28 December 2006]

10 BLAKE, D.; CAIRNS, A. \& DOWD, K. (2000) "Extrapolating VaR by the square-root rule", Financial Engineering News, August, www.fenews. com/fen17/var.html [Date accessed: 14 November 2006]

11 BOLLERSEV, T.; CHOU, R.Y. \& KRONER, K.F. (1992) "ARCH modelling in finance: a selective review of the theory and empirical evidence", Journal of Econometrics, 52: 5-59.

12 BOUCHAUDY, J.P. \& POTTERS, M. (1999) "Worst fluctuation method for fast Value-at-Risk estimates", Service de Physique de l'etat Condense, Centre d'etudes de Saclay, September. http:// ssrn.com/abstract =181949 [Date of access: 11 September 2006]

13 ÇETIN, U.; JARROW, R.A.; PROTTER, P. \& WARACHKA, M. (2004) "Option pricing with liquidity risk", www.orie.cornell.edu/ protter/ WebPapers/bspaper3.pdf [Date accessed: 2 October 2006]
14 COSANDEY, D. (2001) "Adjusting value-at-risk or market liquidity", Risk, October: 115-118.

15 DANIELSSON, J. \& ZIGRAND, J-P. (2006) "On time-scaling of risk and the square-root-oftime rule", Journal of Banking \& Finance, 30(10): 2701-2713.

16 DIEBOLD, F.X. \& LOPEZ, J. (1995) "Modelling volatility dynamics", in Horner, K. (ed.) Macroeconomics: Developments, Tensions and Prospects, Kluwer Academic Press: Boston, MA, pp. 427-472.

17 DIEBOLD, F.X.; HICKMAN, A.; INOUE, A. \& SCHUERMANN, T. (1996) "Converting 1-day volatility to $h$-day volatility: scaling by $\sqrt{h}$ is worse than you think", www.ssc.upenn.edu/ diebold/ [Date accessed: 18 October 2006].

18 DOWD, K.; BLAKE, D. \& CAIRNS, A. (2003) "Long term value-at-risk", www.lse.ac.uk/ubs/pdf/ dp17.pdf [Date accessed: 7 November 2006].

19 ERWAN, L. (2002) "Incorporating liquidity risk in VaR models", June. www.gloriamundi.org/ picsresources/els.pdf [Date accessed: 17 December 2006].

20 FERNANDEZ, F.A. (1999) "Liquidity risk: new approaches to measurement and monitoring", www.sia.com/research/pdf/workingpaper.pdf [Date accessed: 21 November 2006].

21 HAUSMAN, J.; LO, A. \& MACKINLAY, A.C. (1992) "An ordered probit analysis of transaction stock prices”, Journal of Financial Economics, 31: 319-379.

22 HFRX indices. (2006) www.hedgefundresearch. com/hfrx_reg/index.php?fuse $=\operatorname{login} \& 1162138035$ [Date accessed: 12 December 2006].

23 HISATA, Y. \& YAMAI, Y. (2000) "Research toward the practical application of liquidity risk evaluation methods", Monetary and Economic Studies, December: 83-128.

24 HOLTON, G. (2003) Value-at-Risk: Theory and Practice, Academic Press: New York.

25 JARROW, R.A. \& PROTTER, P. (2005) "Liquidity risk and risk neasure computation", Review of Futures Markets, 14(1): 2-17.

26 JARROW, R. \& SUBRAMANIAN, A. (1997) "Mopping up liquidity", Risk, December: 170-173.

27 JARROW, R. \& SUBRAMANIAN, A. (2001) "The liquidity discount", Mathematical Finance, 11(4): 447-474.

28 JP MORGAN. (1996) "Riskmetrics technical document", www.riskmetrics.com [Date accessed: 12 January 2007].

29 LHABITANT, F.S. (2000) "Hedge funds and investment partnerships: a primer", Discussion Paper, Thunderbird, The American Graduate School of International Management: 1-35. 
30 LHABITANT, F.S. (2001) "Assessing market risk for hedge funds and hedge fund portfolios", The Journal of Risk Finance, 2(4): 16-32.

31 LAWRENCE, C. \& ROBINSON, G. (1995) "Liquidity, dynamic hedging and value-at-risk", Risk Management for Financial Institutions: 63-72.

32 LE SAOUT, E. (2002) "Incorporating liquidity risk in VaR models", www.site.voila.fr/erwanlesaout/ eng/rech/abstract.htm\#artc01 [Date accessed: 19 September 2006].

33 LOWENSTEIN, R. (2002) "When genius failed: The rise and fall of long term capital management", Fourth Estate, January, New York.

34 MADHAVAN, A.; RICHARDSON, M. \& ROOMANS, M. (1997) "Why do security prices change? A transaction-level analysis of NYSE stocks”, Review of Financial Studies, 10: 1035-1064.
35 MCNEIL, A.J. (1996) "Estimating the tails of loss severity distributions using extreme value theory", Mimeo: 117-137.

36 MULVEY, J. (2003) "The role of hedge funds for long-term investors", Journal of financial transformation: 23-28.

37 RISK MAGAZINE JOURNALISTS (2004) Private communication.

38 SHARPE, W.F. (1988) "Determining a fund's effective asset mix", Investment Management Review, 2(6), December: 59-69.

39 UMUT, C.; JARROW, R.A. \& PROTTER, P. (2004) "Liquidity risk and arbitrage pricing theory", Finance and Stochastics, 8: 311-341.

40 YAMAI, Y. \& YOSHIBA, T. (2002) "Comparative analyses of expected shortfall and value-at-risk: their validity under market stress", IMES Discussion Paper \#2002-E-2, Bank of Japan: 216-270. 